\title{
How to ensure Quality of Health Accounts
}

Cornelis van Mosseveld ${ }^{a}$, Independent consultant.

a Dignaland 41, 2591 CB, The Netherlands; email: vanmosseveldc@gmail.com

Patricia Hernández-Peña ${ }^{b}$, NIDI researcher; independent consultant

b Lange Houtstraat 29, The Hague, The Netherlands, email: hernandez@nidi.nl

Daniel Arán ${ }^{\mathrm{c}}$, Independent consultant

c Rua Maria Helena Rocha 113 apto 1302 A, Joao Pessoa, Brazil, email: damanter@terra.com.br

Veneta Cherilova ${ }^{d}$, WHO Geneva officer

d Avenue Appia 20, 1211 Geneva 27, Switzerland, email: cherilovav@who.int

Awad Mataria ${ }^{\text {e }}$, WHO Regional Advisor Health Economics and Financing for the Eastern Mediterranean Region

${ }^{\text {e }}$ Regional Office for the Eastern Mediterranean, Abdul Razzak Al Sanhouri Street, Nasr City, Cairo 11371, Egypt, email: matariaa@who.int

Corresponding author:

Patricia Hernández-Peña

Email: hernandez@nidi.nl

Tel: +31623288554

Abstract

Policy makers need up-to-date and reliable information to formulate health policies and monitor their implementation. Given that financing is one of the pillars of the health system, quality of financing data is essential. Quality is a key element but difficult to measure. Increasing quality on financing data involves the use of standard procedures and methods. Current standard framework, the System of Health Accounts 2011, needs to be implemented with checks and controls on the individual as well as aggregated data. Data input on the construction of the accounts and their related metadata are subject to quality measures. In this paper we address a first proposal of the components of the quality in health accounts reporting. The paper assesses quality of health accounts at four stages: (1) Design; (2) Development; (3) Management; and (4) Reporting. It explains what is needed at each stage to ensure reliable results which are fit for informing decision-making. Quality is essential for reliability and trust among all stakeholders, who are responsible of data provision, construction of the accounts and using their results. Quality measurement in health accounts is a reality needing effort. 


\title{
How to ensure Quality of Health Accounts
}

\author{
Keywords: Quality of data; Health Accounts; Policy and quality, Quality indicators
}

\section{Introduction}

Policymakers increasingly need detailed and reliable information to design efficient and effective strategies. Health accounts (HA), the approach to measure financing flows in a health system, provide the critical part of financing information, which is one of the pillars of any health system[1]. HA are a statistical synthesis, integrating scattered data from several sources prepared with various objectives, formats and content. The major quality challenges relate to the data quality, availability and a proper handling of statistical criteria.

To date, a systematic assessment of quality in HA has not been developed. Identified problems refer to a variation in interpretation of classifications and definitions, formulation of assumptions; missing, incomplete and wrong use of data [2]. Lack of uniformity in the process of data handling, and partial use of the classifications, make it difficult to identify data gaps and double counting. These problems lead to reduced comparability and trust of the key policy indicators, such as out-of-pocket payments (OOPs). In 2015 OECD [3] has summarized the problems of estimation of OOPS among their Member States as: a) lack of a standard approach to measure it, b) incomplete coverage, c) wrong coding, d) incomplete metadata. Another recent analysis of health accounts [4] refers also that reports are not accessible, they include partial data, the classes of "other", or "not elsewhere classified" are large, and that year to year data include unexplained major changes.

The target is to reduce the identified problems by implementing the System of Health Accounts (SHA2011) [5], which is the revised version of the previous standard SHA1.0. This internationally agreed framework, has been promoted by the World Health Organization (WHO), Eurostat (Statistical Office of 
the European Community), and the Organization for the Economic Cooperation and Development (OECD), and other international organizations since 2011. Among the advantages of adhering to an international standard is enlarging comparability in time and across countries, gaining shared learning and increasing quality.

This article highlights that although HA deal with diversity of and lacking data sources, ensuring quality of the results is feasible. Policy makers need to get what they expect. After a brief overview of the concept of quality, its applicability in HA is analyzed and finally a set of specific recommendations to deal with the most frequent problems is proposed.

\section{Quality in statistics and in Health Accounts. How to define it?}

There is no universal definition of quality. Commonly, it is expressed as the set of basic rules or prerequisites explicit and known that a product must meet [6]. This leads to an essential inherent feature, a degree of excellence; or a distinctive attribute of a product [7], depending on the viewpoint of the producer or the final consumer. The producer understands that quality is [8] making its product different from others, while "reducing the variation around the target" through a "process" that begins with product design and ends with the intended use. For the customer, quality is the satisfaction that is achieved by the product. Quality is reflected when demand and supply meet, involving communication to accept the possibilities of producers to adapt to the needs of users.

Institutionalization [9] and the use of SHA 2011 induce better quality data in the longer run. Institutionalization deals with data collection, embedding it in the information system; enforcing data production; and promoting data use. It is a process, in which the HA knowledge is maintained in a structural way (people move, organizations stay). It implies that the results are routinely available, timely and used in policy making. The routine improves results of previous years, making this an upgrading process, increasing trust with the suppliers of the data and the users of the information. 
Quality implies how well HA inform decision-making in the health system [10]. The producer and user criteria of quality in statistics are set by the European Union [11][12] and cover the System of National Accounts (SNA) and SHA. For health, the list has been adjusted and complementary characteristics are listed in Figure 1:

Figure 1

Figure 1: Representation of the structure and flow of information

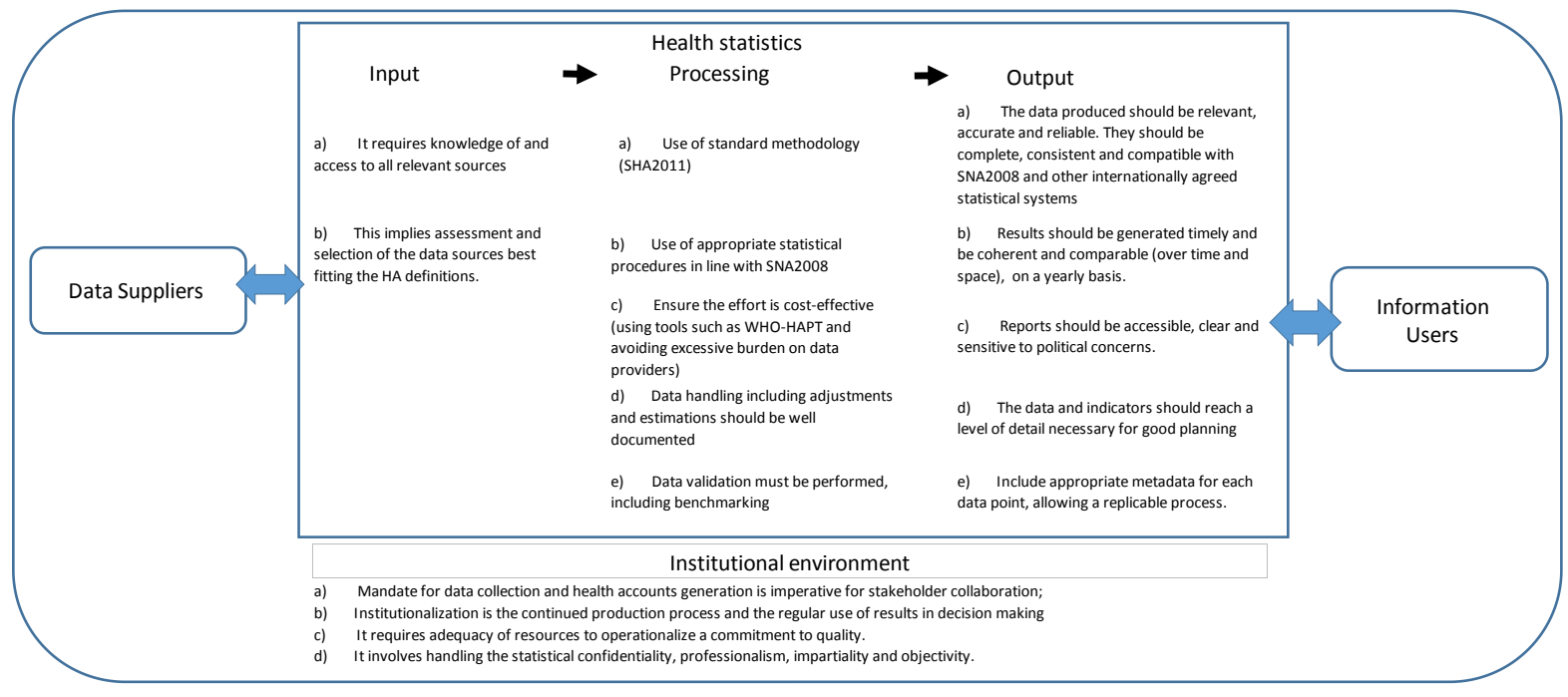

\section{Quality in health accounts: How to achieve it?}

The process of generating a health account can be summarized in four key activities, each of which involve elements of quality:

- Design

- Development

- Management

- Reporting 


\section{Health accounts Design}

As the SNA (SNA2008) [13] reflects economic reality in a country, HA aim at reflecting the reality of the health system. SHA uses SNA rules and principles, with necessary adjustments to apply it at health system level. A good design of the accounts involves the use of an international standard framework. SHA2011 definitions, classifications and accounting rules help to ensure consistency and comparability of the results. The partial or non-use of this standard damages HA quality and hampers international comparisons, which complement and enrich national studies.

The design of HA includes creating the country specific data framework, in the detail needed, enabling to classify all actors and transactions performed, according to consumption, provision and financing of health care. Classifications offer a complementary view of the financing structure and flows under each analytical dimension. According to the framework, the best quality of the accounts requires at least the implementation of 3 classifications: the services consumed, the providers who offered them and the way they were financed, complemented by capital goods invested.

Classification categories are exhaustive and mutually exclusive, enabling to classify each transaction only once, under a policy relevant label. The relationships between categories account for reaching consistency within and across the dimensions. The principles and classification codes are unchangeable.

The understanding of the flows and the actors and transactions involved are key to plan the data collection and analysis: e.g. who performs what, which are their potential funding sources, what are the arrangements for entitlement. This is, to know which information is needed, where to get it and how to use it in a cost-effective way. Quality of HA design requires that people assigned to the activity know the health system and the SHA 2011 methodology. 


\section{Development of health accounts}

The next phase is data collection, data processing and validation. A prerequisite is data availability and accessibility. An exhaustive search of data sources is needed. The available information, likely to be scattered, has different purposes and formats. The task includes choosing comprehensive, most reliable and appropriate data, with SHA matching definitions.

The data collection process is related to the information system: sometimes only aggregates are displayed and the task is finding information to distribute the spending from the highest to the lowest level of aggregation (top down). Sometimes, available data relates to detailed spending classes, which need to be aggregated (bottom-up process). Most of the times bottom-up and top-down processes are combined, leading to more complete and better information.

Data processing refers to classifying expenditure and involves treatment of insufficient or deviant information to make data compatible. It implies the standard use of labels, codes and its related content, facilitating data interpretation in a comparable way, regardless its original purpose and characteristics. For example, a tax declaration interpretation is different for health accounts and taxes. The process involves updating, standardizing, and de-duplicating records to create a single view of the data, even if originating from multiple separate systems. The continued quality concerns are ensuring exhaustiveness and avoiding double counting.

What does it mean if a value of a classification item is not included? A non-applicable category should be left empty, but leaving a relevant blank due to lacking information distorts the results. It supplies the wrong information to users and policymakers. An effort to populate the policy relevant categories is needed.

The level of detail is important. Aggregates are useful for global level monitoring. At national level more detailed information is needed, while even more for program management purposes. The standard 
includes the expenditure distribution by disease and other beneficiary characteristics. Global initiatives such as Sustainable Development Goals (SDG), non-communicable diseases (NCD), Reproductive, Maternal, Neonatal and Child Health $(\mathrm{RMNCH})$, require details not always available or able to be obtained by disaggregating most relevant classes. They may need to be calculated or estimated. Quality of results implies consistency in estimations. Examples of the most frequent problems found in the reports are presented in Table 1.

Table 1 
Table 1: Examples of problems and their proposed solutions

Problems

Boundary deviating from standard, SHA011

Example: Spending on social care related to Long Term Care should be excluded

Use of accounting rules deviating from standard, SNA 2008

Example: Medicines purchased in bulk by the government should only reflect the year of use and exclude the rest of the multiyear purchase.

\section{Double counting}

Example: Records of donor grants and NGOs spending; records of donor grants and government spending; should not be added, without verifying possible overlaps

\section{Lack of detail of data}

Example: The subclass of vaccination should not be left empty. Health insurance administration should not be left empty

\section{Misclassifications of functions}

Examples: - prevention includes partly the value of treatment in some programs and it should be separated.

- Lack of clarity of when to report consumption of medical goods, such as condoms and bed-nets as prevention or as retail sale.

- Administration should not include salaries of all employees of the institution (e.g. social security organization) but only the salaries of employees that are actually involved in administration and management of health services.

Misclassification of beneficiary categories

Example: Appropriate beneficiary/risk groups should be identified

\section{Non-standard use / processing of data}

Example: Estimations produced using population as the basis in context with lack of universal coverage

\section{Errors in original records and surveys used}

Example: Spending on activities performed should not be reported when the payment is done but when the consumption was made.

Information systems usually display a limited number of data needed and the development of small sampling surveys, the use innovative survey techniques [14][15], and other national accounts strategies 
may be necessary. Data treatment requires financing and not financing data [5, op cit pp 96, 241, 242, 290, 336]. These strategies emphasize the need of collaboration with National Accounts (NA) officers, a linkage that leads to the additional benefit of benchmarking to NA data.

There is a strong link between data quality, resources available for HA production and time allocated to the process. Information to assess and plan health policy should preferably be available with only a oneyear delay. HA and policy are both facing an old dichotomy between "time and accuracy". These two things, ample time and sufficient resources to create statistical rigorous results as required by the user, are not always fully available. Adequate resources help to ensure data quality.

The aim is to reach the "best estimate" at the moment of production. It means that all necessary steps were followed, and that estimations and adjustments are appropriate. It implies that once better sources or better methods are available, results may change. The best estimate reflects the reality at a given point in time.

\section{Data Management}

Data management is a core activity, key for reproducibility, completeness and all other statistical criteria of quality. It involves a cross cutting effort beginning with planning, collecting and processing the data.

A "database" must be built to compile the scattered records, to facilitate the use of each record for the various analytical dimensions and for tracking the linkages through the flow. This means that all the data and information to be used should be structured, easy to identify and accessed even after the release of the report, in order to keep an institutional memory of the process. It should also be organized in such a way that assessment of consistency and coherence of distributions are facilitated and controllable. These and additional advantages are integrated in a tool to support the data management, the "health accounts production tool" [16], promoted by WHO. 
Data management also relates to the adequate use of time and keeping track of the big picture. It should consider as well the update frequency of data and the progressive access to better sources. This means that although a best estimate can always be achieved, a progressive improvement in filling the preconditions and collecting inputs will produce better accounts. Data management also involves the stakeholders' participation and their views and suggestions.

\section{Reporting}

Information is to be used. Results can be presented ranging from a concise indicator, a statistical table, to a full report. The data release should facilitate access, interpretation and use, notably related to policy relevant concerns.

The minimal expected quality involves reporting both the results and the complete metadata (data on data), describing the production process, the information sources and procedures followed. The metadata should allow for replicability of the estimates. In particular, all data processing should be detailed, how this was made, which distribution keys were used, and notably, if there was a deviation from the standard framework. The data maturity (preliminary, revised, estimate, etc.) shows the strengths and weaknesses of the data, the remaining gaps, as well as the possible improvements important in a next year's exercise. Revealing weaknesses implies that users are aware and act accordingly.

The final step is the decision of what and how to publish including the level of detail and a selection of policy relevant indicators relating HA information and other sources (such as GDP and population) as presented in table 2 .

Insert table 2 
Table 2: A selection of indicators and their policy relevance

\begin{tabular}{|l|l|}
\hline \multicolumn{1}{|c|}{ International Data Indicator } & \multicolumn{1}{|c|}{ Policy relevance } \\
\hline $\begin{array}{l}\text { Total current health expenditure plus capital } \\
\text { spending }\end{array}$ & $\begin{array}{l}\text { Total burden of the health branch in de } \\
\text { economy }\end{array}$ \\
\hline Current health expenditure & Value of health care consumption \\
\hline Preventive \& Curative spending & $\begin{array}{l}\text { Informs on distribution between types of care; } \\
\text { Helps monitor actual allocation of funds. }\end{array}$ \\
\hline Inpatient \& Outpatient spending & $\begin{array}{l}\text { Informs on distribution between services; } \\
\text { Helps monitor actual allocation of funds. }\end{array}$ \\
\hline $\begin{array}{l}\text { Value of services by hospitals and ambulatory } \\
\text { providers }\end{array}$ & $\begin{array}{l}\text { Informs on distribution between providers; } \\
\text { Helps monitor actual allocation of funds. }\end{array}$ \\
\hline $\begin{array}{l}\text { Government and compulsory contributory } \\
\text { schemes }\end{array}$ & $\begin{array}{l}\text { Checking of the level of one of the Universal } \\
\text { Health Coverage dimensions }\end{array}$ \\
\hline Out-of-pocket expenditure on health & $\begin{array}{l}\text { Burden of health spending on households and } \\
\text { financial risk protection. Checking of the level of } \\
\text { one of the Universal Health Coverage } \\
\text { dimensions }\end{array}$ \\
\hline Externally funded expenditure on health & $\begin{array}{l}\text { Dependence and sustainability of health system } \\
\text { funding }\end{array}$ \\
\hline Total health allocation by government & $\begin{array}{l}\text { Fiscal space (government's efforts towards the } \\
\text { health sector) }\end{array}$ \\
\hline $\begin{array}{l}\text { Total pharmaceutical expenditure } \\
\text { Remuneration of human resources }\end{array}$ & $\begin{array}{l}\text { Importance of two main cost drivers in the } \\
\text { health system }\end{array}$ \\
\hline $\begin{array}{l}\text { Net acquisition of machinery and equipment } \\
\text { infrastructure }\end{array}$ & \begin{tabular}{l} 
Investment efforts in the health sector \\
\hline
\end{tabular} \\
\hline
\end{tabular}

\section{Quality and quality control is a continuous process}

Quality controls are an integral part of the accounting process used from the start (planning and data collection) up to the end (dissemination of the results). Quality controls are needed to assure that different sources for different variables for the same year, or for different years for the same variable, are compatible with each other. Integration of the various sources is one of the most important aspects to warrant quality. Integration includes also the elimination of data entry errors. Regular checks on the consistency of the data and their relations are needed along the process.

Before data release, a set of quality control measures is performed ranging from very simple checks such as is the aggregate equal to the sum of the parts - to verification of the plausibility of aggregates 
and components. Validation is one of the basic steps in any accounting process and is a guarantee for quality. This involves four stages:

1. Validating each data point. A double check is performed using similar data/information from at least two different sources. The reliability of the data point is to be verified in the national context, including the assumptions and the allocation keys used in the calculations and distributions. Metadata should confirm the validity of the data.

Detecting outliers is more difficult as it involves the evaluation of the relative change in the variable under verification as well as a relative change of its related components. To decide if any correction is needed, the data and metadata needs to be reviewed, considering external factors such as policy changes as the cause.

2. Consistency of aggregates is verified through their components, their definition and data content. It includes all expenditure by class and relevant actor. Aggregates allow for understanding relationships between the dimensions of the system. The result of this analysis is to guide adjustment of variables, data points, identify potential data gaps and determining the performance or need of a supplementary search. The comprehensiveness is violated when more than $20 \%$ is missing.

3. Validation by major stakeholders, including national authorities. Discussion of partial and integrated results helps not only to ensure they are appropriate but also that the process contributes to the appropriation of the results by the authorities. It identifies the need to incorporate, refine or correct data or assumptions. This process contributes to an increase in confidence in this process by the stakeholders.

4. The capacity to adapt after each validation round is essential because the process can result in a need for change, due to availability of previous lacking information or misinterpretation of data. The ability to introduce these corrections improves reliability and quality of information. 
The results of all validation steps provide an initial assessment of quality considered in a static approach, which should be extended to become a dynamic process in which the data of different periods are being compared. Monitoring the continued process can involve new procedures. E.g. to use trends: the result of a yearly series of estimates are useful to detect any implausible change. At the moment, the standard framework can be used to verify the aggregates and their interactions to monitor the quality. In the "current situation" the minimal requirements are not always met. The ideal is to reach a systematic oversight and progressive improvement, as proposed in table 3. The generation of general and/or country specific algorithms, could give a more extended coverage of this monitoring.

Insert Table 3 
Table 3: Examples of quality indicators

\begin{tabular}{|c|c|c|c|}
\hline Key component & Current situation & $\begin{array}{l}\text { Criterion / indicator } \\
\text { process oriented: } \\
\text { minimum }\end{array}$ & $\begin{array}{l}\text { Criterion / indicat } \\
\text { process oriented: } \\
\text { Ideal }\end{array}$ \\
\hline Structure & $\begin{array}{l}\text { Not always included functions and } \\
\text { capital }\end{array}$ & $\begin{array}{l}\text { Providers } x \\
\text { Functions } x \\
\text { Financing schemes + } \\
\text { capital }\end{array}$ & $\begin{array}{l}\text { All classifications } \\
\text { necessary for poli } \\
\text { makers }\end{array}$ \\
\hline $\begin{array}{l}\text { Coverage of actors } \\
\text { 'providers, } \\
\text { financing agents, } \\
\text { 'evenues, } \\
\text { ichemes,.....) }\end{array}$ & $\begin{array}{l}\text { Not always included Other } \\
\text { ministries, some subnational } \\
\text { spending, Traditional, } \\
\text { Complementary, Alternative } \\
\text { Medicine payments, NGOs and } \\
\text { private medical insurance, (lacking } \\
\text { all or their administration } \\
\text { spending), e trade and informal } \\
\text { payments, In total > } 20 \% \text { missing }\end{array}$ & $\begin{array}{l}\text { In number } 80 \% \text { of } \\
\text { the main actors; }\end{array}$ & $\begin{array}{l}\text { In contribution } 80 \\
\text { of the main actors }\end{array}$ \\
\hline $\begin{array}{l}\text { Jut-of-pocket } \\
\text { Jayments }\end{array}$ & $\begin{array}{l}\text { Not always triangulated, some } \\
\text { missing components can be large } \\
\text { as e-trade, some non-health } \\
\text { components included as } \\
\text { transportation and even } \\
\text { transportation for accompanying } \\
\text { persons, sometimes included } \\
\text { insurance premiums. These errors } \\
\text { are not evident if metadata is not } \\
\text { consulted. }\end{array}$ & $\begin{array}{l}\text { Based on household } \\
\text { survey triangulated } \\
\text { with provision } \\
\text { (medical goods) } \\
\text { Included informal } \\
\text { health payments (e- } \\
\text { trade, under the } \\
\text { table payments, } \\
\text { illegal and non- } \\
\text { formal health } \\
\text { payments) } \\
\text { Excluded non health } \\
\text { components (e.g. } \\
\text { transportation) } \\
\text { Excluded non OOPs } \\
\text { components (e.g. } \\
\text { insurance } \\
\text { premiums) }\end{array}$ & $\begin{array}{l}\text { Verified at provid } \\
\text { level } \\
\text { Triangulated with } \\
\text { national accounts } \\
\text { private consumpt } \\
\text { components } \\
\text { Benchmark is } \\
\text { national accounts } \\
\text { (notably for OOPs } \\
\text { although not } \\
\text { exclusively) } \\
\text { Goal is <20\% } \\
\text { (Universal Health } \\
\text { Coverage), } \\
\text { benchmark withir } \\
\text { the peer group of } \\
\text { countries (by } \\
\text { income, disease } \\
\text { burden) }\end{array}$ \\
\hline $\begin{array}{l}\text { Availability of detail } \\
\text { for policy making }\end{array}$ & $\begin{array}{l}\text { Reports may present only } \\
\text { aggregates }\end{array}$ & $\begin{array}{l}\text { Current health } \\
\text { expenditure at } 1^{\text {st }} \\
\text { digit of each } \\
\text { classification }\end{array}$ & $\begin{array}{l}\text { All items which ar } \\
\text { policy relevant fol } \\
\text { the country at the } \\
\text { level needed }\end{array}$ \\
\hline $\begin{array}{l}\text { All relevant } \\
\text { ndicators }\end{array}$ & $\begin{array}{l}\text { Usual discontinuity of reported } \\
\text { indicators }\end{array}$ & $\begin{array}{l}\text { Yearly estimates for } \\
\text { monitoring }\end{array}$ & $\begin{array}{l}\text { Yearly estimates } \mathrm{f} \\
\text { monitoring }\end{array}$ \\
\hline Metadata & $\begin{array}{l}\text { Not always accessible, incomplete, } \\
\text { and does not describe data } \\
\text { procedures }\end{array}$ & $\begin{array}{l}\text { Sources, coverage, } \\
\text { estimated items, }\end{array}$ & $\begin{array}{l}\text { All information } \\
\text { needed to evaluat } \\
\text { the results includi }\end{array}$ \\
\hline
\end{tabular}




\section{User satisfaction and results}

Quality is defined at the moment the data/products are used. From the data users' viewpoint, satisfaction is observed when the information provided reflects health system reality of the country and when it is easily accessible, interpretable, transparent and policy relevant. Health accounting users are a wide variety of institutions and persons, ranging from Ministries, academia and the press, to individuals interested in health and the processes surrounding the statistics and policies.

As a user, governments and policy authorities shall be satisfied when the health accounts information allows them to develop new policy measures, evaluate policy outcomes, or for accountability of resource use and governance. Good quality data assists reforms to meet the desired planned objectives, based on financial evidence. Good information can suggest appropriate policies while inadequate information induces wrong conclusions and decisions. The ethical responsibility of health accounts developers is central to the efficient use of community resources. Accountability is a prerequisite and facilitates proper resource use.

The process of appropriation of information by national authorities and stakeholders in the system leads to a demand for more detail and creates more confidence. This makes that the accounts become richer and specific in a process of continuous improvement to satisfy the new quality demands.

\section{Discussion}

Health accounts are produced to support decision making. The challenge of quality in health accounts is thus linked to policies. The quality of HA has been a recurrent concern both of producers and users [2, $3,4]$. However, to date, there is still no a systematic measure of quality of HA. This paper proposes a first step towards a commitment of quality in the production of HA and of monitoring the quality of the HA results. The proposed approach is embedded in the generation process. Different approaches lead to different results. Using the same datasets but applying slightly different statistical techniques and 
assumptions can lead to differing results in the details (category and distribution level). These differences can create confusion in the users and require validation/explanation [17]. As not many "how to" guides are available for health accountants[18][19][20], the approach presented in this paper can be a starting point. OECD has developed some validations of estimation procedures[21] . It is likely that the process can be used by lower and middle income countries (LMIC). However, part of the evidence to be created is the analysis of the transference of these procedures to weaker statistical structure countries.

A precondition for the measurement of quality is the use of the global standard (SHA2011 framework). It implies also the compliance of the associated standard accounting procedures and estimation techniques. Non-compliance to the standard leads to comparability problems as demonstrated in a recent systematic review [4].

Governments and other users have an implicit perception of the quality of every HA report and results. To put some flesh to the bones of quality a set of exemplary indicators was proposed in table 3 considering the key areas on HA generation. Quality can be measured in many ways. The proposed indicators range from those related to the level of completeness such as the number of actors in the system and the number of due entries left blank; to the consistency among aggregates, its components, and the number of not justifiable outliers; up to the estimation of details of household payments and all the related meta-information. The willingness to offer transparency is relevant to quality improvements.

Country statistical maturity plays also a role and imposes a challenge to quality of the whole process: statistical environment implies to have or not, enough, complete, reliable data sources. For example, in most LMIC the measurements of the level of OOPs is basic for the assessment of financing policies[22]. One of the most frequently used data sources are household surveys, which are infrequent and not always comply with standardized content. Data on household consumption should be compared/complemented with data on services provided and/or financed [23]. National Accounts work 
this approach and have regularly data on provision and consumption. Cooperation with national accountants can be profitable in sharing data and procedures for a standard handling of the various data challenges. A technical capability to adjust to the statistical needs is part of the solution.

This proposal provides examples of operational indications of how to achieve comprehensive quality in health accounts and how to measure it. It is fully compatible with various analysis of HA problems with a more specific data scope, such as Bui et al, and Calcoun et al. Calcoun et al's approach focuses on a single country and a specific component. It represents an illustration of the more general proposal, which can lead to further refinement of the criteria and process to suit country specific needs. Several other studies are not directly linked with the new standard (SHA 2011) but include many useful hints and procedures, most of them still valid to warrant quality[24].

HA quality can be part of a more extended process. In a majority of countries, the hospital sector is the single biggest spending and output generating part of the health branch. The introduction of spending indicators linked to the hospital quality control system is strategic. E.g. hospital morbidity and its spending are a measure of hospital services quality[[25]. Specific examples are the number of cesarean sections), the number of repeated surgeries and their spending, the number of antibiotic resistant hospital infections and the associated spending, the spending and number of doctors or nurses per bed.

Adaptability of reporting to policy changes and concerns is another characteristic of quality. For example, a cut or increase in budget for hospitals or salaries, has repercussions. Cutting red-tape, reducing bureaucracy and administrative burden are valid political goals but often lead to loss of useful information. How well these can be reflected in the estimations? This is a quality aspect to consider.

To answer some of the policy concerns the accounts require specific detail. This is the case of nonrecorded payments such as under-the-table, fraud and corruption. Fraudulent actions require a validation system. Only a careful checking of each bill paid by the insurance company or the government 
or each remuneration makes it possible to detect all fraud. However, to check all bills can be difficult and instead, a systematic sample or random verification is envisioned. Activities related to corruption are currently difficult to identify in the accounts.

\section{Conclusions}

Health accounts quality is not a fiction. Five major areas to consider to assure quality in HA are proposed:

1. The use of the standard methodology that condenses the long experience in health accounting and benefits its users (see figure 1). The proposal here contained is a stepwise approach considering all HA production steps.

2. Problems found in the generation of health accounts are frequently related to the lack of understanding of the standards (SHA 2011 and the SNA2008) and how to apply these in the specific situations of the national health system under analysis (see table 1). A deep knowledge of the national health system and its information system are also mandatory.

3. A yearly production of the health accounts contributes to quality as a process. This is complemented by successive expenditure estimates incorporating lessons learned from the previous years.

4. The interaction between the producers and the users defines the indicators that can be used for answering relevant national policy questions. Different layers of quality controls are useful: national and international [26]. Trust and transparency of the process will allow the accessibility of the reports and a better cooperation of the stakeholders.

5. To monitor the quality of the HA the paper proposes specific indicators exemplified in table 3 . The process of assuring quality, however, may require an expanded set of actions, which goes from facilitating the knowledge and use of the standards, to establishing the analysis of the accounts related to their uses, the analysis of their methods and disseminating the best practice, 
through a community of practice and an observatory. A selected list of proposals is included in table 1.

To summarize, Health Accounts integrates scattered data from different sources, objectives, formats and content and provides policy relevant answers. The process of the construction of the accounts involves cooperation with all stakeholders. All stages of the creation of the accounts includes elements that can warrant and increase quality. Indicators - the main vehicles to convey messages to policymakers - can be used to monitor the quality. 
References:

1. World Health Organization. Health systems web statement. WHO, Geneva, 2015. Accessed on $2^{\text {nd }}$ October 2015. http://www.who.int/healthsystems/strategy/en/

2. Calcoen P, Moens D, Verlinden P, van de Ven WPMM, Pacolet J, Improved estimates of Belgian private health expenditure can give important lessons to other OECD countries, , Health Policy 119 (2015) 341-355

3. OECD. DELSA/HEA/HA (2015)5. Results of the supplementary questionnaire on sources and methodology for Out-of-Pocket payments, OECD, Paris, 2015.

4. Bui LA, Lavado RF, Johnson EK, Brooks BPC, Freeman MK, Graves CM, et al. National health accounts data from 1996 to 2010: a systematic review. Bulletin of the World Health Organization 2015;93:566-576D. doi:http://dx.doi.org/10.2471/BLT.14.145235

5. OECD, Eurostat, WHO. A System of Health Accounts 2011, OECD Publishing 2011. Doi: 10.1787/9789264116016-en

6. ISO 9001 Quality Management Systems 2015. ISO Website. Accessed 4 October 2015. http://www.iso.org/iso/home/standards/managementstandards/iso 9000/iso9001 revision.htm?=

7. Derived from http://www.merriam-webster.com/dictionary/quality

8. Adapted from http://www.qualitydigest.com/html/qualitydef.html

9. Maeda, A, Harrit, MN, Mabuchi, S, Siadat, B, Nagpal, S. Creating Evidence for Better Health Financing Decisions. World Bank. Washington. 2012

10. Poullier JP, Hernandez P, Kawabata K. National Health Accounts: Concepts, Data Sources, and Methodology. In: Christopher JL Murray and David B. Evans (Eds). Health Systems Performance Assessment. Debates, Methods and Empiricism. Chapter 16, p 185-194. WHO. Geneva 2003. http://www.who.int/pub/2003/hspa/en/

11. Eurostat, ESS, European Statistics Code of Practice. For the national and community statistical authorities. $28^{\text {th }} \quad$ September $2011 . \quad$ Luxembourg http://ec.europa.eu/eurostat/documents/3859598/5921861/KS-32-11-955-EN.PDF/5fa1ebc690bb-43fa-888f-dde032471e15;

12. Quality Assurance Framework of the European Statistical System. Luxembourg 2012. http://ec.europa.eu/eurostat/documents/64157/4392716/qaf 2012-en.pdf/8bcff303-68da43d9-aa7d-325a5bf7fb42

13. European Communities, International Monetary Fund, Organization for the Economic Cooperation and Development, United Nations, World Bank. System of national accounts 2008. Brussels, Luxembourg, New York, Paris, Washington, 2009.

14. Supreme Council of Health. Qatar National Health Accounts Report - 2011. A Trend with a New Classification. State of Qatar. Doha. 2012

15. Bill \& Melinda Gates Foundation. No Time to Lose: Fulfilling Our Family Planning Promise to 120 Million Women. Gates Foundation Website. Accessed 12 March 2016. http://www.gatesfoundation.org/Media-Center/Press-Releases/2015/11/Family-PlanningPromise

16. WHO, USAID, HF\&G, ABT Assoc, Prognoz. Health Accounts Production Tool SHA 2011. WHO website. Accessed 4 October 2015. http://www.who.int/health-accounts/tools/en/

17. AbouZahr, C. New Estimates of maternal mortality and how to interpret them: choice or confusion?, Reproductive Health Matters, 2011:19(37):117-128 
18. OECD. Extension of work on expenditure by disease, age and gender. Paris, France, 2013

19. Rannan-Eliya, RP. Estimating Out-Of-Pocket spending for National Health Accounts, World Health Organization, Geneva. 2010; http://www.who.int/healthaccounts/documentation/estimating OOPs ravi final.pdf

20. OECD, WHO. Guidelines for the implementation of the SHA 2011 framework for accounting health care financing. OECD, Paris, 2014

21. OECD. Capital expenditure in the health sector. In Health at a Glance 2015: OECD Indicators. Paris, 2015

22. Rannan-Eliya, R. P. and Lorenzoni L. Guidelines for Improving the Comparability and Availability of Private Health Expenditures Under the System of Health Accounts Framework. OECD Health Working Papers, No. 52, OECD. Paris, 2010 http://dx.doi.org/10.1787/5kmbrcg0clvc-en

23. Bernard D, Selden TM, Pylypchuk YO. Aligning the Medical Expenditure Panel Survey to Aggregate U.S. Benchmarks, 2010. Agency for Healthcare Research and Quality Working Paper No. 15002. Rockville, 2015

24. Ke, X, Ravndal, F, Evans, DB, Carrin, G, Assessing the reliability of household expenditure data: Results of the World Health Survey, Health Policy 91 (2009) 297-305

25. Van der Laan, J, et al, HSMR 2013: Methodological report 2014|47, Statistics Netherlands, The Hague/Heerlen, 2014

26. 26. IMF. Quality assessment framework. Data Quality Reference site. IMF, 2012, Washington D.C., http://dsbb.imf.org/Pages/DQRS/DQAF.aspx 